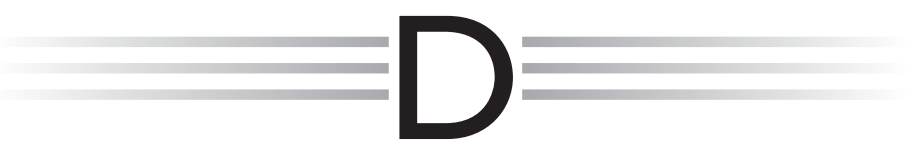

\title{
Common Laboratory Findings in Pregnancy
}

During pregnancy, laboratory values change and vary due to the physiological changes that occur. It is imperative that nurses use the correct pregnancy reference ranges to determine if laboratory findings are within a normal pregnancy range or if variations are present that warrant additional assessment and intervention. Throughout the postpartum period, laboratory findings return to normal.

\section{COMMON LABORATORY VALUES}

\begin{tabular}{lcc}
\hline Blood Component & Nonpregnant & Pregnancy \\
Hgb (g/dl) & $12-16$ & $11-14$ \\
Hct (\%) & $37-47$ & $33-39$ \\
WBC (SI units) $\times 109 / \mathrm{L}$ & $4-11$ & $6-16$ \\
PLT (SI units) & $150-400$ & $150-400$ \\
PCV (\%) & $37-47$ & $33-44$ \\
RBC (million/mm $\left.{ }^{3}\right)$ & $4.2-5.4$ & $3.8-4.4$ \\
MCV (fl) & $80-100$ & $70-90$ \\
MCH (fl) & $27-34$ & $22-31$ \\
\hline
\end{tabular}


COMMON LABORATORY VALUES (continued)

\begin{tabular}{lcc}
\hline Blood Component & Nonpregnant & Pregnancy \\
MCHC (fl) & $32-35$ & $32-35$ \\
Reticulocyte (\%) & $0.5-1$ & $1-2$ \\
Serum ferritin $(\mathrm{ng} / \mathrm{mL})$ & $25-200$ & $15-150$ \\
Serum Iron (mcg/dL) & 135 & 90 \\
Iron binding capacity (mcg/dL) & $250-460$ & $300-600$ \\
Transferrin saturation (\%) & $25-35$ & $15-30$ \\
Iron (mcg/dL) & 135 & 90 \\
Red blood cell folate $(\mathrm{ng} / \mathrm{dL})$ & $70-85$ & $70-500$ \\
\hline
\end{tabular}

\section{CLOTTING RISK STUDIES}

\begin{tabular}{lcc}
\hline Blood Test & Nonpregnant & Pregnant \\
Activated PTT (seconds) & $26.7-36.5$ & $29-34.8$ \\
Thrombin time (seconds) & $16.9-20.9$ & $18.3-26.5$ \\
Fibrinogen (mg/dL) & $198-314$ & $401-545$ \\
Factor VII (\%) & $79.9-118.7$ & $133.4-229.4$ \\
Factor $\times(\%)$ & $82.3-113.1$ & $124.4-164.6$ \\
Plasminogen (\%) & $91.4-119.6$ & $112.7-155.7$ \\
tPA (ng/mL) & $2.1-9.3$ & $3.5-6.5$ \\
Antithrombin III (\%) & $85.7-112.1$ & $64.2-130.5$ \\
Protein C (\%) & $65.2-89.2$ & $48.7-83.4$ \\
Total protein S (\%) & $61.6-89.6$ & $39.7-60.1$ \\
\hline
\end{tabular}

\section{RENAL FUNCTIONING AND URINARY SCREENING STUDIES}

\begin{tabular}{lcc}
\hline Lab Value & Nonpregnant & Pregnant \\
Creatinine clearance $(\mathrm{mL} / \mathrm{min})$ & $85-120$ & $110-150$ \\
Plasma creatinine $(\mathrm{mg} / \mathrm{dL})$ & $0.65 \pm 0.14$ & $0.46 \pm 0.13$ \\
Blood urea nitrogen $(\mathrm{mg} / \mathrm{dL})$ & $13 \pm 3$ & $8.7 \pm 1.5$ \\
Urinary protein $(\mathrm{mg} / 24 \mathrm{hrs})$ & $<100-150$ & $<250-300$ \\
Urinary glucose $(\mathrm{mg} / 24 \mathrm{hrs})$ & $20-100$ & $>100$ \\
Plasma urate $(\mathrm{mg} / \mathrm{dL})$ & $4-6$ & $2.5-4$ \\
Urinary amnio acids $(\mathrm{g} / 24 \mathrm{hrs})$ & - & Up to 2 \\
\hline
\end{tabular}




\begin{tabular}{lcc}
\hline Lab Value & Nonpregnant & Pregnant \\
Bilirubin (mg/dL) & $0-0.3$ & $0-1.3$ \\
Total protein $(\mathrm{g} / \mathrm{l})$ & $64-86$ & $48-64$ \\
Albumin $(\mathrm{g} / \mathrm{l})$ & $35-46$ & $28-37$ \\
AST (iu/l) & $7-40$ & $10-30$ \\
ALT (iu/l) & $0-40$ & $6-32$ \\
GGT (iu/l) & $11-50$ & $3-41$ \\
Alk phosphate (iu/l) & $30-130$ & $32-418$ \\
Bile acids $(\mu \mathrm{mol} / \mathrm{l})$ & $0-14$ & $0-14$ \\
\hline
\end{tabular}

\section{COMMON POSTPARTUM LABORATORY VALUES}

\begin{tabular}{lc}
\hline Blood Component & Postpartum \\
Hgb (g/dl) & $10.4-18.0$ \\
Hct $(\%)$ & $30-44$ \\
WBC (Sl units) $\times 109 / \mathrm{L}$ & $9.7-25.7$ \\
PLT $(\mu \mathrm{L})$ & $50,000-100,000$ \\
\hline
\end{tabular}

